\title{
FUNCÇÃO DO PROCESSO
}

Exercicio de um direito é a sua utilisação, isto é, a realisação do poder que elle contem, o gôso das vantagens que elle offerece (Clovis Bevilaqua).

Quem tem um direito, tem ipso facto a faculdáde de exercel-o: assim, o proprietario pode usar e gosar a sua propriedade, oneral:a de diversos modos, permutal-a, doal-a, vendel-a.

Tudo isso são poderes inherentes ao dominio que, na phrase elegante de PACHIONI, é a senhoria plena e ideal da pessôa sobre a coisa ou o poder de dispôr de uma coisa de um modo pelo menos virtualmente universal, segundo FERRINI.

Exercita tambem o individuo o seu direito, provendo á sua defesa, quando desconhecido, ameaçado ou violado por acto injusto de outrem. Tutela do direito é, de certo aspecto, seu exercicio.

A luta pela vida é um facto incontestavel. Não é admissivel, nem tem fóros de scientifica, a doutrina socialista que pretende supprimil-a.

Como elegantemente diz Aber. Andrade, na conhecida e magnifica dissertação "A vida do direito civil", "da luta entre os atomos nascem as molleculas; da luta cellular provêm as plastidas e os organismos superiores. Na vida das sociedades observa-se com precisão a mesma concorrencia, que se traduz por phenomenos variadissimos, physiologicos, economicos, politicos e intellectuaes. Pode-se 
dizer com Novicow (Les luttes entre societès humaines et leurs phases successives) que o universo é um complexo de systemas, que se constituem e dissolvem perpetuamente, apresenta-se como um conjuncto de allianças e combates"

$\mathrm{O}$ homem, com effeito, sempre llutou e lutará pela sua liberdade e pelo seu patrimonio material e moral.

Ninguem explanou melhor o assumpto que o grande IHERING, quando affirma que a luta pela vida é a luta pelo direito, visando a perfeita distribuição da justiça, seja para que a cada um se dê aquillo que lhe pertence, seja para demarcar o circullo de acção dos individuos na esphera de suas actividades, evitando-se, os actos lesivos dos interesses particulares.

Alterum non laedere, suum cuique tribuere - eis ahi principios eternos, que nasceram instinctivamente com a primeira aggremiação humana .

O homem, porem, não pode lutar pelo seu direito, tutelando-o por súas proprias mãos. Impossivel seria a coexistencia social, se não fôsse feita e distribuida a justiça por intermedio e em nome do Poder Social, que é quem faz a lei, limitadora das actividades, a ser imposta coactivamente.

A caracteristica do direito, o seu criterium anatomico, diz Picard (Droit Pur) é justamente a coacção sociàl, que o acompanha como satellite fiel e necessario.

A tutela dos interesses particulares, quando desconhecidos, ameaçados ou violados, cabe indiscutivelmente ao Estado.

Pouco importa indagar, e muito nos afastariamos do nosso objectivo, a quem pertenceu o Poder Social atravez da historia: a principio, estaria em mãos do chefe da tribu, depois teria passado a ser privilegio de alguma casta superior, para, afinal, ser delegado aos juizes, desenhando-se, então, com todas as imperfeições iniciaes, o Poder Judiciario, nas mais remotas civilizações. $\mathrm{O}$ facto, porem, é que a 
Justiça sempre se fez, e por qualquer fórma, em nome de uma autoridade superior.

Não é desarrazoada, todavia, a affirmação dos philosophos-juristas quanto á existencia da vingança privada nas primeiras épocas da humanidade, pois que, na incipiente organisação social, predominavam certamente a vioi'encia, a força bruta e céga. Mas, essa auto-satisfação cessou naturalmente com o apparecimento da lei, ou melhor, dos applicadores.da lei.

No estado actual da civilização, é innegavel que só ao Poder Social cabe a defesa dos direitos individuaes. Os velhos textos axiomaticos impõem-se: "jus privatum sub tutela juris publici latet", ou "non est singulis concedendum quod publice per magistratium possit fiere. :"

Entretanto, em certas occasiões, ao titular do direito assiste a faculdade de protegel-o de alguma fórma, fóra da acção do Poder Social, eis que, pela imminencia do perigo, inefficaz poderia ser, por demorada, essa mesma acção.

Repeillindo a aggressão alheia incontinenti, o individuo defende por si só o seu direito, muito legitimamente, cumprindo até um dever para com a propria sociedade, como diz IhERING.

Ninguem desconhece a legitima defesa e o estado de necessidade, institutos mais pertinentes ao direito penal, mas tambem consagrados pela lei civil de todos os povos civilizados. Como dizem os escriptores, o moderamen inculpatae tutelae é um direito universalmente reconhecido.

No caso de ser o possuidor turbado ou esbulhado, poderá manter-se ou restituir-se por sua propria força, diz o art. 502 do nosso Cod. Civil, comtanto que o faça. llogo; mas, os actos de defesa ou de desforço não podem 
ir além do indispensavel á manutenção ou restituição da posse.

Eis ahi a legitima defesa, a defesa privada, podendo constituir auto-defesa, segundo Chiovenda (Principii di Diritto Processuale Civile), se se tratar de turbação simples, ou auto-satisfação, no caso de desforço incontinenti.

E, quando credores, taes como estalajadeiros, hospedeiros ou fornecedores de pousada e alimento (art. 776 do Cod. Civil) fazem effectivo o penhor legal antes de recorrer á justiça, quem deixará de reconhecer ahi um caso typico de auto-defesa?

Mais raro é o estado de necessidade nas relações de ordem civil. Entretanto, a lei permitte a violação do direito alheio, em certos casos, para evitar mal maior. 0 Cod. Civil, no art. 160, letra $b$, declara que não constitue acto illicito a deterioração ou destruição de coisa alheia afim de remover perigo imminente; taes actos, porem, só se legitimam quando as circumstancias os tornarem absolutamente necessarios, não excedendo os limites do indispensavel para a remoção do perigo.

Recordados esses principios geraes e assentado que só ao Poder Social, em thése, cabe a tutela dos direitos individuaes, vejamos como se exercita essa tutela.

O Estado administra a justiça, exerce a faculdade jurisdicional, por meio de representantes, que são os juizes. Estes, para decidir os litigios, applicam a lei, actuam a vontade da lei.

As regras, os principios que se referem á actuação da lei constituem o processo.

Realmente: de nada serviriam as regras abstractas do direito civil, se não existisse o processo, que lhes dá, no momento opportuno, efficiencia pratica. O processo vivifica o direito civil, actualisa o que é simplesmente potencial.

A theoria do processo deve ser estudada sob o duplo aspecto de sua estructura e de sua funcção. Eis o verda- 
deiro methodo, que do campo biologico passou para o campo sociologico.

Saber qual a estructura do processo é indagar como elle se constituiu, como se vae desenvolvendo; completa-se o estudo com o perquirir-se a sua funcção, a sua finalidade, em duas palavras, porque e com que fim age o processo.

O eminente professor Francesco Carnelutti, da Universidade de Padua, nas suas sábias "Lezioni di Diritto Processuale Civile", diz que a funcção de um instituto resulta da coefficiencia desses dois elementos que acabamos de assignalar: o fim a ser attingido e os meios de que se dspõe para tanto. Quer dizer, a funoção constitue-se dos meios adequados para ser alcançado o fim.

Quaes os fins do processo? Qual a sua legitima funç̧ão?

Deixando de lado as velhas theorias unilateraes, segundo Chiovenda, como, entre outras, a que affirma ser o processo o meio de definir e decidir litigios e a que entende ser elle simpiles meio de coacção para o cumprimento de deveres, podemos dizer que, actualmente, duas são as doutrinas que procuram explicar, com segurança, a verdadeira funcção do processo.

A primeira, a doutrina objectivista, seguida por CHIOvenda, Mortara, Carnelutti, Wach e tantos outros, affirma que o processo, antes de mais nada, tem por funcção immediata e precipua a actuação da lei, a realisação do direito objectivo.

Seguindo orientação diversa, não menos notaveis processualistas declaram que o processo visa a tutela do direito subjectivo. E' o que pensam Lessona, Simoncelli, Mattirolo, para os quaes o processo é um conjuncto de regras ou de actos destinados á occorrer á realisação da tutela juridica.

O brilhante escriptor Mario Bellavitis, em trabalho recente sobre "L'identificazione delle azioni", cita, como 
sustentando essa ultima doutrina, Alfredo Rocco, RoVELLI e outros.

Como se vê, os mestres apontados não são accordes em relação ao assumpto, que é fundamental em Direito Processual.

Acceitamos a doutrina objectivista.

O processo funociona, diz Carneluttr, para a declaração da norma juridica applicavel ao caso sub judice, para a verificação da existencia dessa norma e do facto, dando em resultado a integração em relação a um confilicto determinado de interesses. Accrescenta o mestre italiano: eis ahi a funcção primordial do processo, a applicação imperativa da lei, a applicação obrigatoria da norma juridica a um caso concreto. E, porisso, costuma-se affirmar que o juiz (orgão), declarando o direito, pronunciando a sentença, que põe termo aos litigios, jus dicit, tem jurisdição.

Realmente: desde que surge a demanda, porque os individuos não conseguiram de alguma fórma, compôl-a amigavelmente, e havendo, em consequencia, uma lei, uma norma juridica inobservada, é claro que a jurisdição se resolve na composição do litigio, por meio da sentença judicial, e o processo, que tudo isso realisa, visa a applicação serena e imparcial da lei.

Aliás, de um ponto de vista geral, o processo funcciona principalmente no interesse da collectividade. $\mathrm{C}_{\mathbf{A R}} \mathbf{R}^{-}$ NELUTTI illide facilmente a objeição ex-adverso, segundo a quail é nitido e indiscutivel o interesse particular no processo civil, ao passo que se evidencia o interesse publico no processo penal. 0 citado mestre diz que o processo civil funcciona não no interesse das partes, mas mediante a interesse das partes. Não se discute que a iniciativa deve seja particular (o procedimento ex officio é excepcional), mas o interesse do individuo, legitimo e actual, serve sómente para pôr em actividade o processo. 
Abundando em considerações semelhantes, o grande Chiovenda vê na actuação da lei a funcção constante do processo, que se destina a affirmar a vontade positiva ou negativa da norma juridica.

A escola subjectivista, porem, argumenta em contrario, querendo convencer que, nos litigios, o autor vem a juizo para pedir a tutela de seu direito desconhecido, ameaçado ou viollado, e o juiz, proferindo a sentença, declara, mantem ou ordena a reintegração desse direito. Dahi, a conclusão inevitavel de que o processo é o tutelador do direito subjectivo.

Chiovenda, com engenho subtil, demonstra a fragilidade desse reparo, fazendo vêr que os interessados, quando se dirigem ao juiz, pedem a applicą̧ão da lei ao caso que expõem. $O$ processo é o conjuncto de meios adequados a realizar a lei, com a consequencia immediata e necessaria de protecção aos direitos individuaes.

Se eu adquiro alguma mercadoria num armazem (é este o confronto que nos apresenta CHIovenda), satisfaço o meu desejo, o meu interesse, mas o acto do commerciante em si não visou a satisfação do meu interesse, mas o do seu commercio.

Embóra nos pareça indiscutivel a doutrina objectivista, que encara o processo como o meio de realizar a lei, de tornall-a efficiente, devemos concluir tambem que, com essa integração, ha sempre, por via de consequencia, o reconheciIment'o do direito subjectivo - um como que reflexo da actuação da lei:

Actua-se a lei, pelo processo; reconhece-se, ou melhor, tutela-se consequentemente, o interesse individual. Verso e reverso de uma medalha, diz Carneluttr. Seria absurdo, com effeito, que o processo sómente funccionasse para actuar a lei, se não fôsse justamente para, em consequencia, ser declarado, mantido ou reintegrado o direito individual.

Gabriel de Rezende Filho. 